\title{
Język, literatura, muzyka
}

\author{
Elementary penguin singing Hare Krishna \\ Man, you should have seen them kicking Edgar Allan Poe. \\ John Lennon, 1967 \\ (Sgt. Pepper's Lonely Hearts Club Band)
}

Świadomość związków między językiem a muzyką wydaje się powszechna i głęboko zakorzeniona we współczesnej kulturze. W codziennej komunikacji muzykę opisuje się w kategoriach pierwotnie odnoszonych do języka, mowie i sposobom mówienia przypisuje się zaś cechy muzyczne. Połączenie wypowiedzi słownej $\mathrm{i}$ muzycznej $\mathrm{w}$ śpiewie, na różnych poziomach wyrafinowania konceptualnego i głębi emocjonalnej, stanowi jeden $z$ kluczowych i wszechobecnych elementów kultury popularnej i wysokiej, oddziałując w wymiarach indywidualnych i społecznych.

W twórczości artystycznej oczywiste są wzajemne inspiracje i nawiązania dzieł muzycznych i literackich. Mogą mieć wymiar impulsu indukującego powstanie utworu, swobodnej impresji na jego temat, lecz i świadomie konstruowanych analogii lub relacji między kompozycją muzyczną a dziełem literackim. W obliczu powszechności tego zjawiska ogromnym wyzwaniem staje się wskazanie choćby reprezentatywnych przykładów. Sięgać można zarówno do monumentalnych dzieł muzycznych inspirowanych świętymi księgami, przez usiane muzycznymi odwołaniami powieści Murakamiego, aż po nawiązujące w różnym stopniu do uznanych dzieł literatury utwory sceny rockowej (np. Wuthering Heights lub Sensual World Kate Bush, White Rabbit Jefferson Airplane). Trudno w tym kontekście nie odnotować roli ekranizacji dzieł literackich jako inspiracji dla kompozytorów ilustrujących je odpowiednią muzyką oraz filmów, które powstałym by pełnić rolę ilustracyjną wobec muzyki tradycyjnej oraz współczesnej. Literatura przedmiotu jest również niezwykle bogata, z szeregiem prac o charakterze ogólnym i teoretycznym (np. Brown 1970; Feld i Fox 1994; Meyer 2002), jak i poświęconych konkretnym dziełom, autorom lub epokom (np. Finney 1962; Grim 1988; Martin 1991; Wasilewska-Chmura 2011; Kochanowska 2017).

Naukowa refleksja nad związkami między językiem a muzyką obejmuje olbrzymi obszar, wyznaczony kategoriami analizowanych zjawisk oraz celami i perspektywami badawczymi. W dociekaniach poświęconych genezie języka przewija się artykułowana m.in. przez Darwina, lecz eksplorowana również 
współcześnie teza, że to śpiew dał początki mowie, niekiedy łączona $\mathrm{z}$ przypuszczeniami, że intonacja $\mathrm{i}$ ton $\mathrm{w}$ języku współczesnym mogą być reliktami z okresu, gdy melodia wypowiedzi była głównym nośnikiem znaczenia (Thomas 1995; Corballis 2003; Mithen 2005). Niezależnie od prawdziwości tych hipotez, trudno podważać rolę śpiewu w rozwoju językowym oraz społecznym.

Jednym z głównych aspektów, na którym skupia się badanie podobieństw i różnic między językiem a muzyką jest organizacja struktur hierarchicznych składni wypowiedzi muzycznej i językowej. Zjawiska te nadal budzą zainteresowanie, lecz obecnie głównie z perspektywy dynamicznej, a szczególnie procesu przetwarzania na poziomie układu nerwowego (Patel 1998; Koelsch i in. 2013; Asano i Boeckx 2015). Inspiracją dla analiz muzykologicznych stawały się koncepcje generatywistyczne (Laske 1973; Lehrdahl i Jackendoff 1985; McCormack 1996), jak i - w makroskali - postulaty analizy dyskursu (Nattiez 1990a,b; Agawu 2014). Interesujące możliwości dała szeroko eksploatowana w językoznawstwie teoria optymalności (Prince i Smolensky 2008), znajdując zastosowanie również w analizie materiału muzycznego (np. Gilbers i Schreuder 2002).

Podobieństwa między językiem a muzyką mają jednak wyraźne granice. Jednostki językowe niektórych poziomów niosą znaczenie semantyczne, a ich łączenie prowadzi do modyfikacji lub tworzenia nowych znaczeń. Proces tworzenia wypowiedzi muzycznej można uznać za podobny pod wieloma względami, lecz wykorzystywane w nim jednostki rzadko posiadają łatwe do zidentyfikowania referenty w rzeczywistości pozamuzycznej, zaś modyfikacje ich sekwencji nie niosą systematycznych zmian znaczenia podobnych do tych, z którymi możemy mieć do czynienia w języku.

Warstwę dźwiękową muzyki i mowy łączy i dzieli równie wiele. Głos ludzki, mimo ogromnych możliwości ekspresyjnych, nawet w śpiewie chóralnym dysponuje skromniejszą paletą barw niż orkiestrowe składy instrumentalne. Instrumenty elektroniczne pozwalają operować nieograniczonym spektrum barw dźwięku i ich modulacji. Do wspólnych cech języka i muzyki należy wykorzystywanie różnych wysokości dźwięku (ton i intonacja w języku, skale w muzyce), lecz i tutaj nietrudno dostrzec różnice. W muzyce, przynajmniej w tradycji europejskiej, przeważa tendencja do operowania na dźwiękach o określonych wysokościach bezwzględnych, wynikających z konstrukcji skali muzycznych i przyjętej częstotliwości odniesienia. Intonacja ani ton (leksykalny czy gramatyczny) nie operują na skali bezwzględnej: na wysokość dźwięku wpływają cechy osobnicze, stan emocjonalny i wiele innych czynników. Niekiedy od samej wysokości istotniejszy jest kierunek lub forma jej zmiany. Nie ma jednak wątpliwości, że percepcja wysokości dźwięku w muzyce i w mowie nie pozostają niezwiązane (np. Zattore i in. 2002; Marquez i in. 2007; Gold i in. 2011). Wiele problemów sprawiają próby przenoszenia stosunkowo dobrze zdefiniowanego $\mathrm{w}$ muzyce pojęcia rytmu na grunt prozodii języka naturalnego (London 2012; . Wielu badaczy poszukiwało w rytmie mowy wyraźnej izochronii (np. tendencji do utrzymania stałych odległości czasowych między jednostkami akcentowanymi lub stałych długości sylab; Port 1983) oraz różnego typu miar rytmiczności (Arvaniti 2012). Fonologiczne studia nad iloczasem, w których 
wychodzi się z założenia o jego kategorialności, operują na ograniczonym, skwantyfikowanym repertuarze jednostek (np. sylaba długa vs. krótka, samogłoska długa vs. średnia vs. krótka). Wyodrębnienie tych kategorii w sygnale mowy na poziomie fonetyczno-akustycznym, wyłącznie na podstawie fizycznych pomiarów czasów trwania segmentów, pozostaje zadaniem niebanalnym.

W powyższym kontekście szczególnie interesujące wydają się wyniki badań nad "kolizjami” między systemem prozodycznym danego języka i wymogami kompozycji muzycznej w śpiewie (śpiew w językach tonalnych, lecz także częste problemy z poziomu rytmu, iloczasu i frazowania). Zainteresowanie badawczy budzi wpływ własności prozodycznych rodzimego języka kompozytora na formę jego utworów muzycznych, chociaż badania takie wydają się niezwykle trudne z przyczyn technicznych (Patel i Daniele 2003).

W pracach zmierzających do ustalenia wzajemnych wpływów i związków między muzyką a językiem, w tym ich wspólnego rozwoju na przestrzeni dziejów, jak i u jednostki, ogromne nadzieje pokładano w analizach opartych na śledzeniu aktywności mózgu towarzyszącej przetwarzaniu bodźców językowych i muzycznych. W szeregu publikacji pokazano, że opiera się ono na tych samych podsystemach układu nerwowego (Friederici i in. 2001; Levitin i Menon 2003, Fedorenko i in. 2009). Niekiedy jednak wskazuje się na prawdopodobne różnice charakteru językowych i muzycznych procesów przetwarzania (Patel 1998), wielu zaś badaczy ostrzega przed pochopnym orzekaniu o analogiach między przetwarzaniem językowym i muzycznym (Jackendoff 2009; McMullen i Saffran 2004). Szczególnie efektywny wgląd w te zjawiska umożliwia obserwacja ich zaburzeń, w tym amuzji i jej konsekwencji dla przetwarzania prozodii językowej (np. Liu i in. 2010; Patel 2005; Thompson i in. 2012)

Ten nie pretendujący nawet do miana przeglądu pobieżny komentarz na temat podobieństw, różnic i związków między materią muzyczną i językową i podejściami do ich analizy należy potraktować przede wszystkim jako wskazanie dla ostrożności metodologicznej w interdyscyplinarnych badaniach nad relacjami języka i muzyki. Ze szczególną uwagą warto się odnieść do pojęć podstawowych, z których definiowaniem boryka się zarówno muzykologia jak i językoznawstwo. Równie ważne wydaje się określenie możliwych domen i poziomów analizy języka i muzyki (np. struktury wypowiedzi muzycznej oraz językowej, reprezentacje umysłowe, procesy przetwarzania $\mathrm{w}$ tworzeniu i percepcji wypowiedzi muzycznej i językowej, materia dźwiękowa muzyki i mowy) i ustalenie, na jakich poziomach i w jakich warunkach porównania sa uprawnione, i w jaki sposób najefektywniej doszukiwać się wzajemnych wpływów.

Warsztaty Literatura - Język - Muzyka (Poznań, maj 2017) stały się miejscem inspirującej, interdyscyplinarnej dyskusji muzykologów, literaturoznawców i lingwistów. Składające się na niniejszy zeszyt teksty uczestników tego spotkania dotyczą problemów z odległych od siebie miejsc tak naszkicowanej przestrzeni badań i możliwych podejść metodologicznych.

Piotr Podlipniak proponuje spojrzenie na język i muzykę jako dwa systemy fonologiczne i z tej perspektywy, odwołując się do myśli Humboldta, porównuje ze sobą ich wybrane aspekty i wskazuje na ich uwarunkowane ewolucyjnie, silne 
lecz skomplikowane związki. $\mathrm{Z}$ jednej strony nawiązuje do nerwowego poziomu przetwarzania i procesów poznawczych, poszukując tam wsparcia dla swoich tez, z drugiej - bierze pod uwagę szerokie uwarunkowania kulturowe i cywilizacyjne.

Hanna Kupś i Kamil Burkiewicz analizują pieśni górskie i biesiadne ludu sui pod kątem zgodności sekwencji tonalnych z liniami melodycznymi. Nie potwierdzają hipotezy, że istotnym czynnikiem jest forma gatunkowa, lecz dokonują szeregu innych obserwacji. Stwierdzają, iż powiązanie tonów leksykalnych z określoną wysokością dźwięków jest silniejsze niż tendencja do oddania ich konturów w postaci rozbudowanych figur melodycznych.

Edyta Orman podejmuje próbę porównania przekładu w kontekście muzycznym z przekładem literackim. Na wstępie zastrzega, że pojęcie ,przekładu” nie funkcjonuje w nauce o muzyce, zwracając się ku transkrypcji muzycznej, polegającej na przełożeniu dzieła z jednego na inny sposób notacji (np. z obecnie już nieużywanego na współczesny), ale również opracowaniu zapisu dla innego instrumentu lub grupy instrumentów. Perspektywy przyjęte przez Gadamera i Georgiadesa Autorka traktuje jako źródła narzędzi pojęciowych do mówienia o przekładzie, rozumianym również jako wyrażanie treści za pomocą innych środków niż te, które były użyte pierwotnie.

O „niewyrażalności” w muzyce i poezji traktuje tekst Renaty Dobkowskiej. Autorka analizuje piosenki oparte na tekstach Juliana Przybosia i Tadeusza Różewicza, skomponowane zaś przez Tadeusza Łuciuka. Tło tych rozważań, a zarazem źródło niektórych wątków stanowią zarówno historia literatury, jak i filozofia, a centralny wątek to różnica w postrzeganiu możliwości wyrażeniowych słowa u dwóch poetów.

Problemowi przestrzeni w muzyce poświęciła swój tekst Katarzyna Placzek. Autorka rozważa różne możliwości rozumienia tego pojęcia i jego znaczenia dla analizy dzieła muzycznego, zwracając uwagę, że nadal stosunkowo najczęściej postrzega się muzykę jako sztukę operującą w przestrzeni czasu. Szczególną uwage skupia na zagadnieniach literackości i ilustracyjności przestrzeni w muzyce programowej XIX-go wieku. Obiecujące wydają się możliwości nawiązania do osiągnięć naukowych dotyczących funkcjonowania przestrzeni w języku i w poznaniu w ogóle (np. Bryant 1997; Bloom 1999; Levinson 2003).

Jakub Chrenowicz analizuje system zapisu muzycznego, stosowany przez Witolda Lutosławskiego w utworach z elementami aleatoryzmu kontrolowanego. Sam aleatoryzm oznacza wprowadzenie do utworu losowości lub dowolności wykonawczej - pozostawienie pewnych aspektów wykonania czynnikowi losowemu lub, częściej, nadzwyczajną swobodę wykonawczą, której nie należy jednak utożsamiać z improwizacją. Autor systematycznie analizuje różne aspekty notacji stosowanej przez Lutosławskiego, dowodząc, że system ten może być interpretowany jako język formalny programujący działania dyrygenta i orkiestry.

Fakt, że język i muzykę nadal często uznaje się za zjawiska wyjątkowe i charakterystyczne wyłącznie ludzkiej kultury z pewnością stanowi motywację do ich lepszego poznania (Lerdahl i Jackendoff, 1983; McDermott i Hauser 2005; Patel, 2006; Jackendoff 2009; Wallace i in. 2017). Ich efektywne badanie wymaga jednak od lingwistów i muzykologów ogromnej otwartości na dowody zewnętrzne, w tym osiągnięcia neuronauki oraz studiów nad ewolucją. Zawarte 
w niniejszym zeszycie teksty posiadają niezbędny potencjał, by zainspirować czytelnika do elastycznego, holistycznego, uwrażliwionego zarówno na aspekt kulturowy, jak i podłoże nerwowe i ewolucyjne, myślenia o języku, literaturze i muzyce.

\section{Literatura cytowana}

Agawu, Kofi 2014. Music as discourse: Semiotic adventures in romantic music. Oxford: Oxford University Press.

Arvaniti, Amalia 2012. The usefulness of metrics in the quantification of speech rhythm. Journal of Phonetics, 40(3), 351-373.

Asano, Rie i Boeckx, Cedric 2015. Syntax in language and music: what is the right level of comparison? Frontiers in Psychology, 6.

Bloom, Paul (red.) 1999. Language and space. MIT Press.

Brown, Calvin S. 1970. The Relations between Music and Literature as a Field of Study. Comparative Literature, 22(2): 97-107. doi:10.2307/1769755

Bryant, David J. 1997. Representing space in language and perception. Mind \& Language, 12(3-4): 239-264.

Corballis, Michael C. 2003. From hand to mouth: The origins of language. Princeton University Press.

Evans, Vyvyen i Chilton, Paul 2007. Language, cognition and space. Equinox.

Fedorenko, Evelina, Patel, Annirudh, Casasanto, D., Winawer, Jonathan i Gibson, Edward 2009. Structural integration in language and music: Evidence for a shared system. Memory \& cognition, 37(1): 1-9.

Feld, Steven i Fox, Aaron A. 1994. Music and language. Annual Review of Anthropology, 23(1): 25-53.

Finney, G. L. 1962. Musical backgrounds for English literature: 1580 - 1650. Rutgers University Press.

Gilbers, Dicky i Schreuder, Maartje 2002. Language and music in Optimality Theory. ROA-571.

Gold, Ben, Morgan, Nelson, \& Ellis, Dan 2011. Speech and audio signal processing: processing and perception of speech and music. John Wiley \& Sons.

Grim, William E. 1988. The Faust legend in music and literature (Vol. 1). Edwin Mellen Pr.

Jackendoff, Ray 2009. Parallels and nonparallels between language and music. Music Perception: An Interdisciplinary Journal, 26(3): 195-204.

Knobloch, Ferdinand, Poštolka, Milan, \& Srnec, Jan 1964. Musical Experience as Interpersonal Process: A Contribution to the Semantics of Music. Psychiatry, 27(3): 259-265.

Kochanowska, Agata 2017. Gdy słowo musi być postuszne dźwiękowi. Librecista Ryszard Wagner i jego Pierścień Nibelunga. Wydział Neofilologii UAM w Poznaniu.

Koelsch, Stefan, Rohrmeier, Martin, Torrecuso, Renzo i Jentschke, Sebastian 2013. Processing of hierarchical syntactic structure in music. Proceedings of the National Academy of Sciences, 110(38): 15443-15448. 
Laske, Otto E. 1973. In search of a generative grammar for music. Perspectives of New Music, 351-378.

Lerdahl, Fred i Jackendoff, Ray 1985. A generative theory of tonal music. MIT press.

Levinson, Stephen C. 2003. Space in language and cognition: Explorations in cognitive diversity (Vol. 5). Cambridge University Press.

Levitin, Daniel J. i Menon, Vinod 2003. Musical structure is processed in "language" areas of the brain: a possible role for Brodmann Area 47 in temporal coherence. Neuroimage, 20(4): 2142-2152.

Liu, Fang, Patel, Aniruddh D. Fourcin, Adrian i Stwart, Lauren 2010. Intonation Processing in Congenital Amusia: Discrimination, Identification and Imitation. Brain, 133, nr 6: 1682-93.

London, Justin 2012. Three Things Linguists Need to Know About Rhythm and Time in Music. Empirical Musicology, Rev. 7, 5-11.

Maess, Burkhard, Koelsch, Stefan, Gunter, Thomas C., Friederici, Angela 2001. Musical syntax is processed in the area of Broca: A MEG study. Nature Neuroscience, 4: 540-545.

Marques, Carlos, Moreno, Sylvain, Castro, São Luís, \& Besson, Mireille 2007. Musicians detect pitch violation in a foreign language better than nonmusicians: behavioral and electrophysiological evidence. Journal of Cognitive Neuroscience, 19(9): 1453-1463.

Martin, Timothy P. 1991. Joyce and Wagner: a study of influence. Cambridge University Press.

McCormack, Jon 1996. Grammar based music composition. Complex systems, 96, 321-336.

McDermott, Josh i Hauser, Marc 2005. The origins of music: Innateness, uniqueness, and evolution. Music Perception: An Interdisciplinary Journal, 23(1), 29-59.

Meyer, M. J. (red.) 2002. Literature and music. Rodopi.

Mithen, S. 2005. The singing Neanderthal. London: Weidenfeld \& Nicholson.

Nattiez, Jean-Jacques 1990a. Can one speak of narrativity in music?. Journal of the Royal Musical Association, 115(2): 240-257.

Nattiez, Jean-Jacques 1990b. Music and discourse: Toward a semiology of music. Princeton University Press.

Patel, Annirudh D. 1998. Syntactic processing in language and music: different cognitive operations, similar neural resources? Music Perception: An Interdisciplinary Journal, 16(1): 27-42.

Patel, Annirudh D. 2005. The relationship of music to the melody of speech and to syntactic processing disorders in aphasia. Annals of the New York Academy of Sciences, 1060(1): 59-70.

Patel, Annirudh D. i Daniele, Joseph R. 2003. An empirical comparison of rhythm in language and music. Cognition, 87(1): B35-B45.

Port, Robert 1983. Isochrony in speech. The Journal of the Acoustical Society of America, 73(S1): S66-S66.

Prince, Alan i Smolensky, Paul 2008. Optimality Theory: Constraint interaction in generative grammar. John Wiley \& Sons. 
Thomas, Downing A. 1995. Music and the origins of language: Theories from the French Enlightenment. Cambridge University Press.

Thompson W.F., Marin MM, i Stewart L. 2012. Reduced Sensitivity to Emotional Prosody in Congenital Amusia Rekindles the Musical Protolanguage Hypothesis. Proceedings of the National Academy of Sciences of the United States of America, 109, nr 46 (2012): 19027-32.

Wallace, Emma K., Altschul, Drew, Körfer, Karoline, Benti, B., Kaeser, Amanda, Lambeth, Susan, Waller, Bridget, \& Slocombe, Katie E. 2017. Is music enriching for group-housed captive chimpanzees (Pan troglodytes)? PloS One, 12(3).

Wasilewska-Chmura, Magdalena 2011. Przestrzeń intermedialna literatury $i$ muzyki: muzyka jako model $i$ tworzywo $w$ szwedzkiej poezji późnego modernizmu i neoawangardy. Wydawnictwo UJ.

Zatorre, Robert J., Belin, Pascual i Penhune, Virginia B. 2002. Structure and function of auditory cortex: music and speech. Trends in cognitive sciences, 6(1), 37-46. 